\title{
OPTIMIZATION OF SPECIMEN AND TABS GEOMETRY FOR QUASI-STATIC AND FATIGUE TESTING OF COMPOSITES IN UD 90 LAMINATES
}

\author{
Ch. Schneider ${ }^{*}$, G. Pinter $^{1}$ \\ ${ }^{1}$ Chair of Material Science and Testing of Polymers, Montanuniversität Leoben, 8700 Leoben, Austria \\ * Corresponding author christian.schneider@unileoben.ac.at
}

For the testing of long-term behavior of fiber reinforced polymers (FRP), several testing procedures and specimen geometries are available. The most common specimen geometry is a rectangular specimen with glued-on tabs on every side. When testing unidirectionally (UD) reinforced composite materials with a fiber orientation of $90^{\circ}$, the specimens often fail very close to the tabs. Results of specimen, that fail in this area, cannot be regarded as valid. The influence of clamping is a big challenge, especially for this type of specimen. This was the reason to develop a new test specimen design (shoulder bars and tabs with optimized geometry) with the help of finite element simulation $[1,2]$.

In most industrial cases, the UD90 ${ }^{\circ}$ layers are embedded within layers of other directions, like UD $0^{\circ}$ layers. For an embedded layer, the initiation of first cracks in many cases do not lead to failure of the entire laminate. Rather, matrix cracks are retained in the neighboring layers and additional cracks accumulate to a saturation state before the crack grows again [3]. Therefore, it was useful to get an overview on the influence of ply interaction of the layers.

In this work the new specimen geometry was used to analyze the quasi-static and fatigue properties of UD $90^{\circ}$ carbon fiber reinforced polymer (CFRP) as well as glass fiber reinforced polymer (GFRP) laminates. For the evaluation of mechanical properties for the different layups and designs, monotonous tensile tests were performed. Subsequently, experimental S/N-curves (stress amplitude vs. number of cycles) were carried out at different load levels and compared with results of standard rectangular specimens [4].

It could be shown, that with the new specimen geometry in most of the cases, the failure occurred in the test field area and so the results are valid for evaluation. Furthermore, there was a shift of the $\mathrm{S} / \mathrm{N}$-curves to higher number of cycles at the same stress level. Also, it could be shown, that the failure stresses in the embedded $90^{\circ}$ layers are higher than in the UD $90^{\circ}$ specimen, because the crack growth within the embedded $90^{\circ}$-plies is hindered by the additional UD $0^{\circ}$ plies and so the first crack does not lead to specimen failure and multiple cracks accumulate.

\section{References}

[1] Ch. Schneider, M. Drvoderic, G. Pinter, C. Schuecker, Ch. Gaier "Fatigue characterization of embedded layers in CFR Composites". In: Procedia Structural Integrity 19, S. 370-379; 2019

[2] Ch. Schneider, M. Drvoderic, C. Schuecker, G. Pinter "Optimization of the Specimen Geometry of Unidirectional Reinforced Composites with a Fibre Orientation of $90^{\circ}$ for Tensile, Quasi-Static and Fatigue Tests". In: KEM 809, S. 594-597; 2019

[3] W. Grellmann, S. Seidler „Kunststoffprüfung“ München: Carl Hanser Verlag GmbH \& Co. KG; 2011

[4] R. Talreja "Fatigue of Composite Materials" In: Holm Altenbach und Wilfried Becker (Hg.): Modern Trends in Composite Laminates Mechanics. Vienna, s.l.: Springer Vienna (International Centre for Mechanical Sciences, Courses and Lectures, 448), S. 281-294; 2003 